\title{
Is there an inherent limit to acute migraine treatment efficacy?
}

\author{
Marcelo E. Bigal · Tony W. Ho
}

Received: 14 September 2009/Accepted: 20 September 2009/Published online: 10 October 2009

(C) Springer-Verlag 2009

In the current issue of Journal of Headache and Pain, Tfelt-Hansen [1] suggests that calcitonin gene-related peptide (CGRP) receptor antagonists (CGRP-RA) offer relief to only a fraction of patients. To support his hypothesis, he points out that only around two-thirds of migraineurs receiving intravenous (IV) olcegepant achieved pain relief in $2 \mathrm{~h}$, and $46 \%$ of patients had pain relief in $1 \mathrm{~h}$ [2], figures that are lower than previously reported values for subcutaneous sumatriptan [3]. He also considers that the therapeutic gain for oral telcagepant $300 \mathrm{mg}[4,5]$ was modest. He concludes by saying that "...there is most likely an inherent limit to the response one can expect from CGRP receptor antagonists, such as olcegepant and telcagepant, in the acute treatment of migraineurs as a group."

The issues raised by Dr. Tfelt-Hansen are certainly of interest and may be expanded outside the CGRP-RA class. In other words, is there an inherent limit to acute migraine treatment efficacy overall? Before sharing our opinion on this matter, a few considerations on the topic are warranted.

First, endpoints used in acute migraine trials do not measure the effectiveness of a drug for individual patients. Instead, these endpoints measure the effectiveness of the drug for a given population (e.g. $2 \mathrm{~h}$ pain free is a measure of the proportion of patients that are rendered pain free at $2 \mathrm{~h}$ ). In other words, if drug $\mathrm{A}$ is showed to be $5 \%$ more effective than drug $\mathrm{B}$, the conclusion is that $5 \%$ more patients are likely to respond to drug A versus drug B, but no conclusions can be drawn about the magnitude of response in an individual patient. Indeed, on an individual

M. E. Bigal $(\bowtie) \cdot$ T. W. Ho

Merck Research Laboratories,

Whitehouse Station, NJ, USA

e-mail: marcelo_bigal@merck.com patient basis, it may very well be that drug B provides greater benefit than drug A.

Second, the author bases his arguments on the fact that $2 \mathrm{~h}$ pain-free and pain-relief rates for olcegepant and telcagepant are "not impressive", when compared to the triptans. This is questionable. Around $66 \%$ of those receiving IV olcegepant had pain relief. For telcagepant, in a head-to-head phase 3 trial, 2-h efficacy was similar to the efficacy of zolmitriptan $5 \mathrm{mg}$, a very effective triptan [4]. Nonetheless, as stated above, this simply means that when comparing groups, similar proportions of patients responded to telcagepant and zolmitriptan (for the primary endpoint). It may be that patients responding to telcagepant have different characteristics than, or benefit differently from, patients responding to zolmitriptan.

Third, although responses at $2 \mathrm{~h}$ are certainly clinically meaningful, are endorsed by the Clinical Trial Guidelines of the International Headache Society [6], and are accepted by the regulatory agencies, it is still not clear whether these endpoints are the most important for patients [7]. Indeed, as migraine attacks may last many hours and may recur following initial relief, endpoints measuring sustained relief of pain are of importance. Accordingly, when evaluating whether migraine medications have a ceiling effect it is important to consider the parameters to be assessed, rather than relying solely on 2 -h endpoints. Studies assessing patient's preference are of importance in order to validate the use of endpoints in terms of patients' perceptions of benefits [8]. Patients may define efficacy in terms that are individual, largely variable from one patient to the other, and may encompass several attributes of a drug (e.g., speed of efficacy, duration of efficacy, tolerability, ease of use, efficacy on associated symptoms, etc.) [9-12].

While the triptans have a well established mechanism of action and clinical profile, the science beyond the new class 
of the CGRP-RA is just emerging, and the relative advantages of one class over the other are still to be defined. Nonetheless, as previously mentioned, the core question of Dr. Tfelt-Hansen is relevant. Is there an inherent limit to CGRP-RA acute treatment efficacy? We would suggest that there is but, equally, that there is an inherent limit to the efficacy of other classes of acute treatment including the triptans. Migraine is a complex, multisymptomatic disorder, influenced by genetic and environmental factors, with clinical manifestations that vary considerably within attacks and across patients [13]. Several neurotransmitters and neuromediators are involved in migraine pathophysiology, and migraine is the ultimate result of a complex neural network dysfunction that leads to an over-sensitive brain [13]. Different patients will certainly respond differently to different classes of medications [14], and while some patients respond to triptans, some do not. The same is true for other classes of medications, and will surely be the same for the CGRP-RA class. Large unmet migraine treatment needs still exist and some of them should be addressed by the class of CGRP-RA (e.g., triptan failures, contraindications to triptans, patients with risk factors for cardiovascular disorders or using serotoninergic medications) [15, 16]. Given the complex pathophysiology of migraine, no single drug is expected to treat all patients and this fact motivates, and should continue motivating, the development of new classes of migraine drugs.

Conflict of interest Dr. Bigal and Dr. Ho are full-time employees of Merck Research Laboratories. They own stock and stock options from Merck.

\section{References}

1. Tfelt-Hansen P (2009) Is there an inherent limit to the efficacy of calcitonin-gene related peptide receptor antagonists in acute migraine treatment? A comment. J Headache Pain. doi:10.1007/ s10194-009-0157-8

2. Olesen J, Diener HC, Husstedt IW, Goadsby PJ, Hall D, Meier U et al (2004) Calcitonin gene-related peptide receptor antagonist
BIBN 4096 BS for the acute treatment of migraine. N Engl J Med 350(11):1104-1110

3. Tfelt-Hansen P, De Vries P, Saxena PR (2000) Triptans in migraine: a comparative review of pharmacology, pharmacokinetics and efficacy. Drugs 60(6):1259-1287

4. Ho TW, Ferrari MD, Dodick DW, Galet V, Kost J, Fan X et al (2008) Efficacy and tolerability of MK-0974 (telcagepant), a new oral antagonist of calcitonin gene-related peptide receptor, compared with zolmitriptan for acute migraine: a randomised, placebo-controlled, parallel-treatment trial. Lancet 372(9656):21152123

5. Ho TW, Mannix LK, Fan X, Assaid C, Furtek C, Jones CJ et al (2008) Randomized controlled trial of an oral CGRP receptor antagonist, MK-0974, in acute treatment of migraine. Neurology 70(16):1304-1312

6. Tfelt-Hansen P, Block G, Dahlof C, Diener HC, Ferrari MD, Goadsby PJ et al (2000) Guidelines for controlled trials of drugs in migraine, 2nd edn. Cephalalgia 20(9):765-786

7. Lipton RB, Bigal ME, Goadsby PJ (2004) Double-blind clinical trials of oral triptans vs. other classes of acute migraine medication-a review. Cephalalgia 24(5):321-332

8. Solomon J (2008) How strategies for managing patient visit time affect physician job satisfaction: a qualitative analysis. J Gen Intern Med 23(6):775-780

9. Bigal M, Rapoport A, Aurora S, Sheftell F, Tepper S, Dahlof C (2007) Satisfaction with current migraine therapy: experience from 3 centers in US and Sweden. Headache 47(4):475-479

10. Diamond S, Bigal ME, Silberstein S, Loder E, Reed M, Lipton RB (2007) Patterns of diagnosis and acute and preventive treatment for migraine in the United States: results from the American Migraine Prevalence and Prevention study. Headache 47(3):355363

11. Ifergane G, Wirguin I, Shvartzman P (2006) Triptans-why once? Headache 46(8):1261-1263

12. Bigal M, Krymchantowski AV, Lipton RB (2009) Barriers to satisfactory migraine outcomes. What have we learned, where do we stand? Headache 49:1028-1041

13. Goadsby PJ, Lipton RB, Ferrari MD (2002) Migraine-current understanding and treatment. N Engl J Med 346(4):257-270

14. Lipton RB, Cutrer FM, Goadsby PJ, Ferrari MD, Dodick DW, McCrory D et al (2005) How treatment priorities influence triptan preferences in clinical practice: perspectives of migraine sufferers, neurologists, and primary care physicians. Curr Med Res Opin 21(3):413-424

15. Recober A, Russo AF (2007) Olcegepant, a non-peptide CGRP1 antagonist for migraine treatment. IDrugs 10(8):566-574

16. Tepper SJ, Cleves C (2009) Telcagepant, a calcitonin generelated peptide antagonist for the treatment of migraine. Curr Opin Investig Drugs 10(7):711-720 